\title{
A descriptive study to assess the knowledge and practice among adults regarding prevention of Dengue
}

\author{
${ }^{*}$ K.Ramu, ${ }^{* *}$ K.Balasubramanian, ${ }^{* * *}$ Abhilash Charles.
}

\begin{abstract}
:
Objectives: To assess the knowledge and practice to prevent the incidence of dengue fever urban areas in Tumkur,. Methods: Materials and methods: Pre-experimental one group pre- test and post- test design with 510 were selected through convenient sampling technique. Results: The result showed that out of 510 subject 152 had inadequate knowledge level, 258 had moderate knowledge level, 100 had adequate knowledge level and 298 had poor practice level, 110 had average practice level, 102 had good practice level, there was a significant difference between knowledge and practice and also revealed that there was significant association between knowledge and practice with age, education, occupation, place of living, religion, source of information. Conclusion: study conclude that knowledge and practice is significantly associated with each other in prevention of dengue fever among selected individuals in urban areas of Tumkur.
\end{abstract}

\section{Keywords: Knowledge, Practice \& Dengue}

\section{INTRODUCTION}

Dengue fever is commonly known as "break bone fever" for classical symptoms of severe joint And muscle pain and high fever. The factors contributing to the spread of dengue include migration, urbanization and perhaps global warming among others. The first isolation of dengue virus was reported from India in $1964^{1}$.

Dengue fever can vary from mild to severe. Patients who develop the more serious forms of dengue fever usually need to be hospitalized. The best way to prevent the disease is to avoid being bitten by mosquito's altogether. There areapproximately $\quad 390 \quad$ million peopleworldwide infected with the dengue viruseach year, over three times as many as the
World Health Organization's estimate of up to 100 million².

Around 2.5 billion people, or $40 \%$ of the world's population, live in areas where there is a risk of dengue transmission. Symptoms of infection usually begin 4-7 days after the mosquito bite and typically last 3-10days ${ }^{3}$.

Dengue fever can be commonly found in urban parts of subtropical and tropical areas. Dengue is just as prevalent in urban districts of its range as in rural areas.

According to the World Health Organization (WHO) approximately 2.5 billion people, or two-fifths of the world's population, are now at risk from dengue. The disease is now endemic in over 100 countries $^{4}$.

*Professor, Shridevi Insitute of Nursing ,**Professor, KMCH College Of Nursing , ***Asst.Professor, Shridevi Insitute Of Nursing. 
The WHO declares dengue and dengue hemorrhagic fever to be endemic in south asia and become a major public health concern. Despite increasing incidence of dengue in India in recent years, only few studies were conducted on dengue fever. A cross sectional study was conducted on residence of rural and urban areas of east Delhi. This study reported that $82 \%$ of residences were aware of dengue, knowledge about dengue was fair to good. Mosquito was known to be spread the disease to $75 \%$ rural and $89 \%$ urban respondents. More than two third of the urban respondence and two fifth in rural area had used some method of mosquito control or personal protection 5 .

The researcher found to be desirable to evaluate knowledge and practice of the individuals about prevention of dengue fever and people must need to update their knowledge regarding dengue fever. An informational pamphlet consists of figures which help to draw the attention of people and an informational booklet not only effective for people but also it can be used by any person incommunity6.

\section{MATERIALS ANDMETHODS}

Non experimental approach and descriptive survey design was adopted for this study. Five hundred and ten individual's from Kuripalya urban area of Tumkur were selected through convenient sampling technique. Individuals who met inclusion criteria, were available and willing to participate at the time of data collection were included in the study. The tool consisted of a 2 parts. Part 1: Demographic variables to elicit the baseline data of the individuals, which include age, sex, education, occupation, family income, area of residence, marital status, religion, source of information on prevention of dengue fever and part 2 to elicitthe knowledge and practice of the individuals regarding the prevention of the dengue fever. The tools were translated into regional Kannada language by Kannada expert. The knowledge questionnaire consisted of 40 multiple-choice questions and for the correct option the score 1 and for incorrect option 0 . was given. The score ranged from a minimum of 0 to maximum of 40. The practice check-list consisted of 10 closed ended questions. The scoring scale consists of 3 options-always, sometimes, and never. The score for positive stated item for always is 2, sometimes is 1 and never is 0 for negatively stated item foralways 0 , sometime 1 and never 2 . To interpret the level of knowledge, the score subjected as follows: inadequate knowledge $(<50 \%)$, Moderate knowledge (50-75\%), adequate knowledge ( $>75 \%)$. To interpret the level of practice, the score subjected as follows: Poor $(<50 \%)$, Average $(50-75 \%)$, adequate $(>75 \%)$. The tool was validated by 5 experts from the field of nursing and medical The tool was checked for reliability and it was done by Karl spearman co-efficient. Prior to data collection District Health officer, Tumkur. Consent to participate in the study was obtained from each subjects. Confidentiality was assured. After collection of the data, an informational pamphlet was distributed to thesubjects.

\section{RESULTS}

\section{Description of demographicprofile:}

The majority of the subjects age between 30-40(168) and majority of the individuals were females(277) than male(233). Illiterates were more in the study (222) than literates. The major occupation of the individual is cooli (282). Individual are residing majorly in urban area (403), majority of the subjects are married (347), Majority of subject belongs to Hindu religion(241). 
Majority of the individual's monthly income, below 5000(308) and the health profession (266) is the major source of information.

\section{Knowledge interpretation of the individual in prevention of dengue fever:}

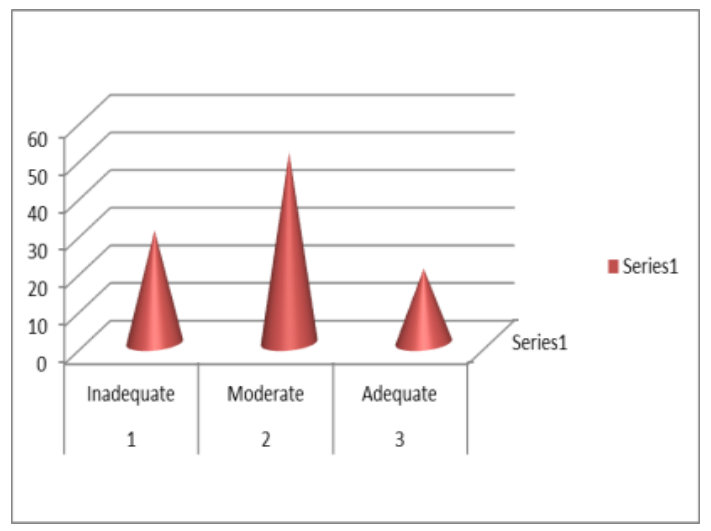

Fig-1: Knowledge Level of individuals regarding Prevention of Dengue fever.

The fig-1shows that knowledge of individuals regarding prevention of dengue fever was determined with mean of 348.27and standard deviation of 328.15.The maximum possible score is 40.The mean score percentage was computed and it was observed as 217.6. This study depicts that, from 510 individuals, 152(29.8\%) were having inadequate $\mathrm{k} \mathrm{n} \mathrm{o} \mathrm{w} \mathrm{l} \mathrm{e} \mathrm{d} \mathrm{g} \mathrm{e} \mathrm{,258(50.5 \% )}$ were having moderate knowledge and remaining $100(19.6 \%)$ of them had good knowledge.The maximum possible score was10.The mean score was 5.83 with standard deviation 41.34.The mean score percentage was 19.43.This shows that individual's knowledge regarding prevention of dengue fever were found to bemoderate.

III. Practice interpretation of the individual in prevention of dengue fever.
Fig-2: Practice Level of individuals Regarding Prevention Of Denguefever.

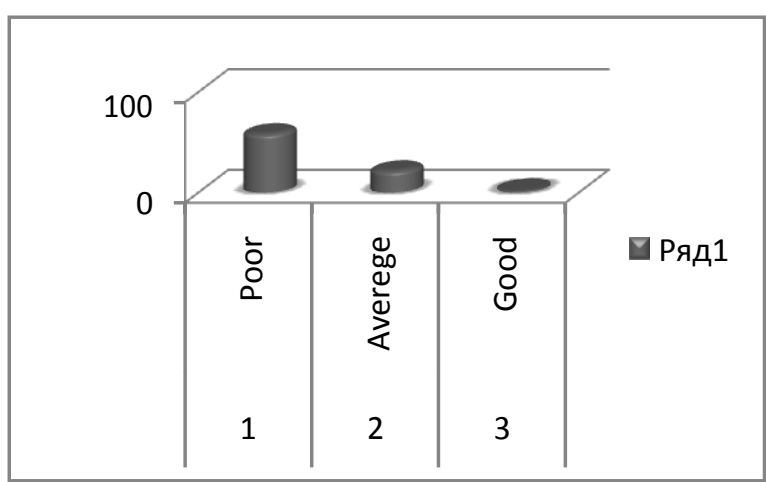

Fig-2 shows that practice of individuals regarding prevention of dengue fever was determined with mean of 5.83 and standard deviation of 41.37 , of all 510 individuals, $298(58.43 \%)$ had poor practice, $110(21.56 \%)$ had average practice and only $102(2.0 \%)$ have adequate level of practices regarding prevention of dengue fever. It shows that majority of individuals had poor practice regarding prevention of Dengue fever.

\section{IV.Correlation between Knowledge and Practice of individuals regarding prevention of dengue fever. $\mathrm{N}=\mathbf{5 1 0}$}

\begin{tabular}{|l|l|l|l|l|l|c|}
\hline $\begin{array}{l}\text { S. } \\
\text { no }\end{array}$ & $\begin{array}{l}\text { Subjec } \\
\text { ts }\end{array}$ & $\begin{array}{l}\text { Max } \\
\text { Possib } \\
\text { le }\end{array}$ & Mean & S.d & $\begin{array}{l}\text { Correlat } \\
\text { ion }\end{array}$ & $\begin{array}{c}P \\
\text { value }\end{array}$ \\
\hline 1 & $\begin{array}{l}\text { Knowle- } \\
\text { dge }\end{array}$ & 40 & 348.27 & $\begin{array}{l}32 \\
9.1\end{array}$ & $\begin{array}{l}\text { Sig, } \\
0.933\end{array}$ & 0.01 \\
\cline { 1 - 5 } 2 & Practice & 10 & 5.83 & $\begin{array}{l}41 . \\
3\end{array}$ & & \\
\hline
\end{tabular}

\section{Table-1 $*$ Sig-significant.}

The table shows the outcome of the correlation analysis, which has been attempted to determine the relationship between knowledge and practice. The linear correlation between overall knowledge and practice was $r=0.933$, which was statistically significant at 0.01 level. 
It confirms that individual's knowledge and practice were statistically related i.e. higher the knowledge better would be the practice.

\section{DISCUSSION}

The purpose of this study was to assess knowledge and practices of individuals regarding prevention of dengue fever and it was found that majority of the subjects had moderate knowledge ( $50.5 \%$ ), 29.8\%, had inadequate knowledge and only $19.6 \%$ had good knowledge.

The study finding also revealed that majority of subjects (58.43\%) had poor practices, $21.56 \%$ had average practices and only $2 \%$ had good practices regarding prevention of denguefever.

The findings of the study add strength to the finding of the previous study that good level of knowledge which is not commensurate with practice directed at reducing prevalence of dengue fever ${ }^{7}$. Similar finding were reported by a study conducted among respondents in Samar province, Philippines. The respondents had good knowledge of dengue fever and its prevention, however they faced challenges such as greater access to correct information on dengue fever. There was no correlation between knowledge about dengue and preventivepractices ${ }^{8}$.

The association of demographic variables with knowledge of individuals revealed that variables such as age education, occupation, place of living, family income, religion, source of information were significant at 0.05 level and the association of demographic variables with practices revealed that age, education, occupation place of living, family income, religion were significant at 0.05 levels.

\section{CONCLUSION}

The severity of dengue endemic in India is under estimated by lack of accurate information related to incidence. From the findings of the present study, it can be concluded that the individuals living in urban areas need more awareness and motivation regarding prevention of dengue fever. It is necessary to educate the public regarding prevention of dengue fever through health fraternity. So that there will be reduction of the incidence rate of dengue fever. India urgently needs the permanent dengue surveillance system to monitor and control a mosquito borne viral disease.

\section{REFERENCES}

1. Mike paddock, Dengue fever, symptoms and prevention. Available from www.medicalnewstoday.com/articles/1794 71./2015

2. Lifson AR. Mosquitoes,models and dengue. Lancet1996;347(9010):p-1201-2

3. Gupta p Kumar, Aggrawal P etal.knowledge, attitude and practice related to dengue in rural and uraban slum areas of Delhi.Journal of communicable diseases,2006;30(2):p107-112

4. Kalyani Thivakaran.Dengue and dengue fever. Available from http://www.medindia.net/patients/patientinf o/dengue/2014

5. James Bennett. India faces worst dengue fever outbreak in years with more than 6,500 confirmed cases. Available from http://www.abc.net.au/news/2015.

6. Shamil Shams. India's fight against deadly dengue outbreak. Available from http://www.dw.com/en/indias-fightagainst-deadly-dengue-outbreak/2015

7. Faisal Shuaib, Danatodd, Dianne cambell, John Ethri. Knowledge, Attitude and Practice regarding Dengue infection in Westmoreland, Jamica, West Indian Medical Journal2010;59(2):139-146

8. Amar Taksande, Bhavana Lakhkar. Knowledge, Attitude and Practice regarding Dengue infection in rural area of central India, Shiraz E Medical Journal 2013;13(4):146-15 